\title{
Human uremic serum displays calcific potential in vitro that increases with advancing chronic kidney disease.
}

\author{
${ }^{1}$ Ashish Patidar (MSc), ${ }^{2}$ Dhruv K. Singh (MD), ${ }^{3}$ Peter Winocour (MD), ${ }^{1,2}$ Ken Farrington \\ (MD), and ${ }^{1}$ Anwar R. Baydoun (PhD)
}

\begin{abstract}
${ }^{1}$ School of Life and Medical Sciences University of Hertfordshire, College Lane, Hatfield, AL10 9AB, UK

${ }^{2}$ Renal Unit, Lister Hospital, Coreys Mill Lane, Stevenage, SG1 4AB, UK

${ }^{3}$ Department of Diabetes and Endocrinology, QEII Hospital, Howlands, Welwyn Garden City, AL7 4HQ, UK
\end{abstract}

Running title: In vitro calcific potential of human serum

Author for correspondence: Professor Anwar R Baydoun

School of Life and Medical Sciences

University of Hertfordshire

College Lane

Hatfield

AL10 9AB

Telephone: 01707285120

Fax: 01707285046

e-mail: a.baydoun@herts.ac.uk

Support: This work was supported in part by an unrestricted project grant from Genzyme Therapeutic Ltd, and by the Lister Nephrology Research fund.

Keywords: vascular calcification, calcific potential, chronic kidney disease, human uraemic serum, aortic smooth muscle cell. 


\begin{abstract}
Vascular calcification strongly correlates with declining renal function and contributes to the high morbidity and mortality of patients with chronic kidney disease (CKD). It is closely regulated by circulating factors but little is known about the potential of serum from patients to induce calcification outside the disease setting - the calcific potential of serum. We have therefore examined the ability of serum from age- and sex-matched subjects with and without advancing CKD to induce calcification of cultured smooth muscle cells. Samples from patients with CKD induced significant calcification compared with controls. More importantly, samples from patients on haemodialysis induced significantly higher calcification than those with moderate or advanced CKD. The calcification induced by the latter two but not those on haemodialysis could be enhanced with calcium chloride and $\beta$-glycerophosphate. A positive correlation was evident between measured serum creatinine, phosphate, parathyroid hormone, osteoprotegerin and the degree of calcification in vitro. Estimated glomerular filtration rate, diastolic blood pressure, haemoglobin and serum albumin correlated negatively. Stepwise multivariate analysis of log-transformed calcific potential data highlighted serum creatinine, albumin and osteoprotegerin as significant predictors, explaining around $50 \%$ of the variation. Thus, other regulators either not investigated or as yet unidentified, may contribute to the calcification potential of serum in vitro. Furthermore, uremic serum can induce graded calcification outside of the disease milieu that reflects the degree of kidney impairment in vivo. These findings could have important clinical relevance in terms of developing novel diagnostic and/or therapeutic strategies for subjects with CKD.
\end{abstract}




\section{INTRODUCTION}

Calcification is a common occurrence in end-stage renal failure and shows a strong correlation with declining renal function [1]. It often results in a diverse range of pathologies including calcific uraemic arteriolopathy, solid as well as extra-osseous soft tissue calcification of which vascular calcification (VC) is the most common and often the most clinically relevant corollary. The existence of VC in chronic kidney disease (CKD) results in increased arterial stiffness, becoming predictive of secondary cardiovascular complications with high morbidity and mortality [2, 3].

The precise mechanisms that lead to VC in CKD subjects are poorly understood but it is accepted to be a delicate and well-controlled biological process that results in smooth muscle cells (SMCs) gaining an osteoblastic phenotype [4]. These complex changes may be regulated in vivo by circulating factors in plasma and, interestingly, in vitro by uremic serum especially under hyperphosphatemic conditions [5]. The latter demonstrates that serum from pathological settings may have a potential to induce VC even outside the disease milieu and provides a means through which the mechanisms associated with this process can be investigated. More importantly, the ability of serum to induce calcification in vitro could be exploited to predict the risk of calcification in vivo during routine tests, and applied to the clinical management of patients. To achieve this, a robust biological model is required in which the calcific potential of individual serum samples can be validated, and trends within defined groups of CKD patients identified to allow the establishment of threshold scores which might guide the need for intervention.

We have developed an in vitro model of calcification in smooth muscle cells and embarked on a program of studies to establish the calcific potential (i.e. ability to induce calcification) of individual serum samples from cohorts of patients with CKD. More specifically, we have investigated whether serum from patients with stages 3, 4/5 CKD or on haemodialysis (5D) has a greater in vitro calcific potential than normal age- and sex-matched controls. We also wished to establish whether in vitro calcific potential correlated with the degree of renal impairment. In parallel, we have characterised each patient in terms of disease vintage, extra-renal co-morbidity, and smoking history. Furthermore, we have related the calcific potential of serum in individuals to the levels of biochemical markers and report for the first time that CKD serum induces graded calcification outside of the disease milieu that correlates with the degree of kidney impairment, and with specific biomarkers which may, in part, explain the potential of serum to induce calcification in vitro. 


\section{METHODS}

\section{Ethical approval}

Ethical approval was obtained from the Hertfordshire Research Ethics Committee. The procedures followed were in accordance with the ethical standards of the responsible committee on human experimentation (institutional and national) and with the Helsinki Declaration of 1975, as revised in 2000. The study subjects gave written informed consent prior to recruitment into the study.

\section{Patient recruitment}

All the patients were recruited from the renal clinics in East and North Herts NHS Trust hospitals in Hertfordshire, UK. Inclusion criteria for the patients with CKD were age $>18$ years, glomerular filtration rate (eGFR) by MDRD-4 formula less than $60 \mathrm{ml} / \mathrm{min}$. Exclusion criteria were immunosuppressive therapy, pregnancy, hormone replacement therapy and malignancy. Twenty age- and sex-matched healthy individuals with normal renal function, without diabetes or in vivo calcification as detected with CT scan were recruited as controls. There were 70 subjects in the patient group who, based on eGFR, were classified into a moderate (stage 3 CKD; 21 subjects), advanced (stage 4 and 5 CKD; 18 subjects) or haemodialysis group (5D; 30 subjects). In the 5D group only those patients who had undergone at least 3 months of dialysis were considered.

\section{Data collection}

Demographic and clinical variables including age, gender, and blood pressure were recorded. Blood samples in controls and pre-dialysis patients were collected during routine visits and those of haemodialysis patients were collected immediately before dialysis sessions. Samples were taken into Z serum sep clot activator VACUTTE ${ }^{\circledR}$, centrifuged at $2500 \mathrm{rpm}$ for 15 minutes at $4^{\circ} \mathrm{C}$ and the serum stored at $-80^{\circ} \mathrm{C}$ until analysed.

\section{Biochemical analysis}

Routine biochemistry analyses were conducted for urea, creatinine, and C-reactive protein (CRP). Levels of the latter $>5 \mathrm{mg} / \mathrm{l}$ were considered high. Parathyroid hormone (PTH) concentrations were measured on the Beckman Access ${ }^{\circledR} 2$ immunoassay system (Beckman Coulter, High Wycombe, UK). Assays for osteoprotegerin (OPG), receptor activator of nuclear factor kappa $B$ ligand (RANKL), bone alkaline phosphatase (BAP) were performed on the automated ELISA (enzyme linked immunosorbent assay) analyzer, Triturus ${ }^{\circledR}$ (Grifols, Cambridge, UK). Matrix Gla protein (MGP) was quantified using the BIOMEDICA GRUPEE kit (BI-20062). All analyses were performed in duplicate. 


\section{Isolation and culture of rat aortic smooth muscle cells}

Cells were isolated as previously described [6] using aortic explants obtained from male Wister rats and cultured in Dulbecco's Modified Eagle's Medium (DMEM) supplemented with penicillin $\left(100 \mathrm{U} \mathrm{ml}^{-1}\right)$, streptomycin $\left(100 \mathrm{\mu g} \mathrm{ml}^{-1}\right)$ and either $10 \%$ foetal bovine or human serum.

\section{Induction of calcification in rat cultured aortic smooth muscle cells}

Cells in 96-well plates were allowed to grow to 60-70\% confluency over 48 hours before being incubated with $10 \%$ serum in the absence (Controls) and presence of a widely used standard calcification buffer consisting of $7 \mathrm{mM}$ calcium Chloride $\left(\mathrm{CaCl}_{2}\right)$ plus $7 \mathrm{mM}$ $\beta$-glycerophosphate ( $\beta$-GP) [7]. To ensure that any subsequent mineralisation was regulated and reflective of genuine calcification of cells rather than non-physiological spontaneous precipitation of excess calcium phosphate, parallel experiments were carried out where $\mathrm{CaCl}_{2}(7 \mathrm{mM})$ and $\beta$-GP $(7 \mathrm{mM})$ were incubated either in empty wells or with cells fixed with $10 \%$ formaldehyde. All incubations were terminated after the designated time period which varied from 1 to 7 days.

\section{Determination of calcification and total cell protein content}

Cell monolayers were lysed with buffer consisting of $10 \mathrm{mM}$ TRIS (pH 7.4) and $10 \%$ sodium dodecyl sulphate. Calcification was determined using the DICA-500 $\mathrm{Ca}^{+2}$ assay Kit from Bioassay System (Universal Biologicals, UK), according to the manufacturer's instructions. Total protein content was measured using the bicinchoninic acid (BCA) protein assay as described previously [8]. Once determined, calcium levels in lysates were normalised for total cell protein per well and the data presented as nmoles $\mathrm{Ca}^{+2}$ protein $\mathrm{mg}^{-1}$.

In parallel experiments, cells were viewed at $10 x$ magnification using a Nikon confocal microscope under normal view to visualise plaques formed as a consequence of calcification.

\section{Cell Viability Assay}

Cell viability was determined under the different experimental conditions by assessing the metabolism of 3-(4,5-dimethylthiazol-2-yl)-2,5-diphenyltetrazolium bromide (MTT) to formazan as described previously [8].

\section{Statistical Analysis}

Statistical analysis was carried out using SPSS, version 17 and the data presented as the mean $\pm S D$ for normally distributed, and as median (interquartile range) if not normally distributed. For continuous variables the significance of differences between two groups was determined by student t test (for normally distributed data) and the Mann-Whitney U-tests (for non-normally distributed data). One Way Analysis of 
Variance followed by Bonferroni post-hoc testing or the Kruskal-Wallis test was used to compare multiple groups as appropriate. The Chi-squared test was used to differentiate between the groups with respect to categorical data. Correlations utilised the Pearson and Spearman test as appropriate. For multivariate analysis, values of calcific potential were log-transformed.

\section{Materials}

Cell culture reagents and other general biochemical reagents including $\mathrm{CaCl}_{2}$ and $\beta$-GP were purchased from Sigma-Aldrich (London, UK). Penicillin and streptomycin was from Fisher Scientific (Loughborough, UK) and foetal bovine serum (FBS) from Gibco (Scotland, UK). The BCA protein quantification Kit was from Thermo Scientific (Hemel Hempstead, UK) and the DICA-500 $\mathrm{Ca}^{+2}$ assay Kit was from Universal Biologicals (Cambridge, UK). Reagents for OPG, RANKL, BAP were obtained from Oxford biosystems, Oxford, UK. 


\section{RESULTS}

\section{Demographics and clinical factors}

All subjects were Caucasian. There were no significant differences in age or gender ratios across the groups. Systolic blood pressure (SBP) was significantly lower in the 5D group than in patients with advanced CKD, and diastolic blood pressure (DBP) was significantly lower in the 5D than in both pre-dialysis groups (Table 1).

\section{Baseline biochemistry and hematology}

CKD groups differed significantly from controls with respect to haemoglobin, serum albumin, cholesterol, phosphate, PTH, OPG, and RANKL levels and with respect to OPG/RANKL ratio (Table 1). Serum phosphate increased with advancing CKD while serum calcium was unchanged. Haemoglobin levels were higher in moderate CKD than in the 5D group. Serum albumin was higher in both moderate and advanced CKD groups than in 5D patients. Likewise the proportion with elevated CRP levels was greater in the $5 \mathrm{D}$ group then in both other CKD groups. Bone alkaline phosphatase levels were similar in all CKD groups. Parathyroid hormone and OPG levels were significantly higher in 5D patients than both pre-dialysis groups, whilst RANKL levels and OPG/RANKL ratios did not differ significantly between CKD stages. Matrix Gla protein has so far been determined only in the 5D group in which levels were significantly lower than in controls (Table 1).

\section{Development of an in vitro model of calcification}

In order to be able to determine the effects of serum from human patients on the development of VC, an in vitro model of this process was initially established using rat cultured aortic smooth muscle cells (RASMCs) exposed to $\mathrm{CaCl}_{2}$ and $\beta$-GP as a phosphate source. Each compound was used at a concentration of $7 \mathrm{mM}$ and this was predetermined from pilot studies using $2 \mathrm{mM}$ to $20 \mathrm{mM}$ of either component. At $2 \mathrm{mM}$ there was little or no evidence of calcification, while at higher concentration $(\geq 15 \mathrm{mM})$ $\mathrm{Ca}^{+2}$ precipitated with $\beta$-GP in the medium (data not shown). A $7 \mathrm{mM}$ concentration of each combined was found to give consistent and optimum calcification. As shown in Figure $1 \mathrm{~A}$, incubation of cells for 5 days with complete culture medium supplemented with $10 \%$ FBS resulted in marginal calcification. Inclusion of $7 \mathrm{mM} \mathrm{CaCl}_{2}$ enhanced calcification while $\beta$-GP $(7 \mathrm{mM})$ was without significant effect. By comparison, inclusion of both together caused a marked increase in the calcification which was much greater than the additive effects.

Photographs taken of cells following the different treatment conditions (Figure 1B) revealed a normal monolayer under control conditions with little evidence of calcification as indicated by the lack of calcific plaques. Incubations with $\mathrm{CaCl}_{2}$ at $7 \mathrm{mM}$ showed moderate plaque formation while cells incubated with $\beta$-GP exhibited less marked effects. Consistent with the calcification data (Figure $1 \mathrm{~A}$ ), co-incubations with $\mathrm{CaCl}_{2}$ and 
$\beta$-GP (both at $7 \mathrm{mM}$ ) caused marked calcific plaque formation throughout the monolayer (Figure 1B).

In parallel studies, the time course of calcification was determined over 7 days. The data presented in Figure 1C show a time dependent increase which was evident after Day 3, reaching a peak at Day 5 but declining by Day 7 . This trend was only evident when cells were incubated with $\mathrm{CaCl}_{2}$ together with $\beta$-GP. The basal levels of calcification seen with culture medium alone did not change significantly over time (Figure 1C).

Assessment of cell viability using the MTT assay showed that survival was unaffected at days 1 to 5 but significantly reduced at day 7 as reflected by the marked inhibition of MTT metabolism to formazan (Figure 1D). This decrease in cell viability may account for the decreases in calcification observed at day 7 and as a result all subsequent experiments were carried out over a 5 day period.

\subsection{Effects of human serum on calcification of RASMCs}

Incubation of cells with serum from patients with CKD induced calcification of RASMCs outside the disease milieu. More importantly, there was a graded response in total cellular calcium content and deposition of calcium phosphate crystals. These changes which we have defined as the calcific potential of serum, correlated with the degree of renal impairment. This is clearly evident in Figure 2 which shows that serum from 5D patients had a greater calcific potential than serum obtained from stage 3 or stage $4 / 5$. Control human serum did not cause any obvious calcification of cell monolayers and the total detected levels of calcium (50.8 \pm 9.3 ) were not significantly different to those in cells incubated with FBS $\left(32.2 \pm 8.4\right.$ nmoles $\mathrm{Ca}^{+2}$ protein $\left.\mathrm{mg}^{-1} ; \mathrm{p}=0.30\right)$. These levels are consistent with other studies in smooth muscle cells $[9,10]$. However the degree of calcification in our studies was less, perhaps due to the difference in the species and incubation period.

In the whole group, the calcific potential of serum correlated positively with blood urea, serum creatinine, phosphate, OPG and PTH, and negatively with DBP, haemoglobin and albumin (Table 2). In stepwise multivariate analysis the significant predictors of log transformed calcific potential were serum creatinine $(p<0.001)$, albumin $(p=0.009)$ and OPG $(p=0.010)$. These factors however only explain around $50 \%$ of the variation in calcific potential $\left(r^{2}=0.506\right)$. Other parameters including age, serum cholesterol, phosphate, PTH and high CRP were not significant in this model. The calcific potential of serum could therefore be influenced by other as yet unidentified factors.

In view of the graded response reported above, we were interested in establishing whether the calcific potential of the stages $3,4 / 5$ or $5 \mathrm{D}$ sera could be enhanced under conditions that may be associated with calcification in vivo (such as the presence of high calcium and phosphate). We therefore investigated the effects of co-incubating RASMCs with serum samples and both $\mathrm{CaCl}_{2}(7 \mathrm{mM})$ and $\beta-\mathrm{GP}(7 \mathrm{mM})$. In these studies, the calcific potential of serum from stage 3 and $4 / 5$ CKD groups was 
significantly enhanced whilst no significant increment was apparent with control or 5D samples (Figure 3). Interestingly, within the latter (5D group) we observed that half the samples (referred to here as responders) did show an increase in calcification above that seen with serum alone when co-incubated with $\mathrm{CaCl}_{2}$ and $\beta$-GP while the other half (non-responders) did not (Figure 4). What was even more striking was that responders had significantly higher levels of MGP $(p=0.003)$, high density lipoprotein (HDL; $p=0.004)$ and RANKL $(p=0.012)$ when compared to the non-responders. Serum phosphate was lower and serum albumin higher in the responders but this did not attain statistical significance. Other levels of other potential modulators of calcification in Table 1 were not significantly different between the two groups. 


\section{DISCUSSION}

Although plasma constituents are believed to regulate vascular calcification, it is not entirely clear how the various molecules act, nor is the complex interplay amongst the key factors established. Furthermore, the critical role of each biomarker, in terms of which might be the most important molecule(s) remains unresolved. Of particular relevance to the current manuscript is the additional question about whether their presence in serum may be sufficient to regulate calcification outside of disease settings. If established, the latter may be of clinical significance in defining thresholds of calcific potential and predicting risks of calcification in vivo which might inform therapeutic strategies.

With the exception of studies by Chen et al demonstrating that pooled uremic sera may accelerate calcification in bovine cultured vascular smooth muscle cells, there are no studies that have examined the direct calcific potential of non-pooled serum or its constituents in an in vitro setting [5]. More importantly, the key question of whether the calcific potential of serum is dependent on the degree of renal impairment has not been addressed. We have therefore correlated the degree of in vitro calcification with the severity of renal impairment in vivo and have looked at the association between several biomarkers and the degree of calcification induced in vitro.

In developing our model, we examined the effects of $\mathrm{Ca}^{+2}$ alone, phosphate in the form of $\beta$-GP and a combination of both at pre-determined concentrations. The degree of calcification was less pronounced with $\mathrm{CaCl}_{2}$ and even less so with $\beta$-GP alone but clearly evident when both were used in combination. These results suggest that, on their own, neither $\mathrm{CaCl}_{2}$ nor $\beta$-GP may be sufficient to induce profound calcification, at least in vitro. That this contradicts other studies may be due to differences in the duration of experiments, which in ours were over a shorter period (5 days). Others were prolonged, obtaining calcification after incubations of between 20 to 30 days [5, 11]. It is therefore likely that when used individually, $\mathrm{CaCl}_{2}$ or phosphate may require a longer duration to cause calcification. The advantage of our model however is that calcification was significantly induced and evident within a period during which optimal cells confluency was maintained and viability was not compromised. Moreover, the process was time-dependent supporting the notion that it is regulated and not simply a consequence of aggregation of $\mathrm{Ca}^{+2}$ and phosphate to form crystals. One conclusion we have not been able to draw from our studies is whether the changes we observed involved a change in phenotype or indeed differentiation of the cells into bone-like structures and this remains to be established.

The results obtained with the clinical samples confirm that serum from CKD settings can induce calcification of normal healthy smooth muscle cells in vitro. Moreover, we have provided the first demonstration of this effect being graded, correlating well with the severity of renal impairment in vivo. In the first instance, the 5D sera had the most striking calcific potential which was effectively 2 -fold higher than the increases seen with the CKD3 or CKD 4/5 and at least 8-fold higher than the controls samples. With the limited sample size used in our studies, there was no notable difference in the 
effects obtained with the CKD3 and the CKD4/5 sera but both were significantly higher than baseline values.

The events and mechanisms underlying the effects described above have not yet been investigated. Studies aimed at addressing these are now planned and will include analysis of fetuin A and FGF-23 which are emerging as critical regulators of calcification [12]. In the interim we have analysed our samples for calcium and phosphate as well a number of other putative biomarkers of in vivo calcification and correlated these with the calcific potential of serum in our model.

The first notable observation was that calcium was not significantly elevated above controls nor was it significantly different between the three CKD groups. Phosphate levels on the other hand increased relative to the degree of renal impairment and correlated positively with in vitro calcification. However, in our multivariate model phosphate was not independently associated with calcific potential, suggesting that it may not be critical in this process. This would be consistent with our earlier demonstration that phosphate, on its own, is not sufficient to induce calcification in vitro over periods not associated with detrimental changes in cell survival and viability. Moe et al have also indicated that serum factors other than phosphate may be required for inducing calcification in vitro [13]. These observations do not support other published literature [14-16].

Blood urea, serum creatinine, PTH and OPG also increased in parallel with the severity of renal failure and correlated positively with calcific potential. Although serum creatinine was an independent predictor of calcific potential in our multivariate model it is only a marker of renal dysfunction. Parathyroid hormone on the other hand remains controversial, with some studies claiming elevated levels determine the severity and progression of VC [17] while others have suggested that it may inhibit calcification [18]. To further compound the controversy, other groups have failed to establish a link between PTH and VC in patients with CKD $[19,20]$. There was also no independent association of PTH with calcific potential in our multivariate model suggesting that it is not directly involved in the process. Whilst OPG has been implicated as a key inhibitor of $\mathrm{VC}$ in animal models [21, 22], levels are reported to be elevated in serum from CKD patients on dialysis $[23,24]$ and have been strongly correlated with the severity of coronary calcification $[11,25]$. We found OPG to be independently associated with calcific potential in multivariate modeling, supporting a role in vitro and in the genesis of VC in humans.

Albumin decreased with advancing CKD and was negatively correlated with calcific potential with which it was independently associated in our multivariate analysis. This may still be a reflection of the severity of the degree of renal impairment but may also indicate a regulatory role in the pathogenesis of VC perhaps by inhibiting calcification through attenuation of seeding of calcium phosphate crystals [26]. C-reactive protein and cholesterol which may have roles in the development of in vivo calcification [27] were associated with serum calcific potential in univariate analyses of our data. We did not 
however find evidence of independent association, but this does not preclude a role for inflammation or lipid abnormalities in the in vitro model.

In parallel with establishing the direct effects of serum we also explored whether calcific potential could be enhanced by increasing calcium and phosphate concentrations in the incubation medium. Addition of $\mathrm{CaCl}_{2}$ and $\beta$-GP increased the calcific potential of the predialysis sera but did not alter that of the control or haemodialysis group significantly. The lack of enhancement of the calcific potential of 5D sera led us to examine individual samples more closely and this identified two distinct groups which we have referred to as responders and non-responders. The former showed decreased calcific potential when compared to the non-responders. However, the calcific potential of serum from responders could be enhanced by $\mathrm{CaCl}_{2}$ and $\beta$-GP which was not evident with serum from non-responders. Further analysis of the biochemical parameters revealed that non-responders had significantly lower levels of BAP, HDL, RANKL and MGP. Phosphate levels were higher and albumin levels lower in this group but not significantly so. It may be that in non-responders, the potential to calcify is maximal even before addition of extra calcium and phosphate. In contrast, in responders, perhaps associated with higher ambient levels of inhibitors (e.g. HDL, MGP, RANKL) and lower levels of promoters (ie high albumin and low phosphate), the potential to calcify is sub-maximal, and only fully expressed on addition of extra calcium and phosphate.

In summary, we have developed a model of VC which we have exploited to demonstrate the calcific potential of serum and shown that this correlated with the degree of uraemia in patients. The model appears suitable for screening clinical samples and offers a reproducible but yet simple system that could be employed in predicting risks of calcification in vivo. Additionally, the model can now be utilised to identify critical biomarker surrogates and mechanisms responsible for the calcific potential of the serum. This may lead to the development of diagnostic tools and inform therapeutic strategies. 


\section{Disclosure}

The studies reported in this manuscript were supported partly by an unrestricted research grant from Genzyme.

\section{Acknowledgements}

We are grateful to Bev Summerhayes of the Department of Diabetes and Endocrinology, for patient liaison, data management and clinical sample collection, $\mathrm{Mr}$ G. Sivakumar and Dr Adie Viljoen of the Department of Clinical Biochemistry at the East and North Herts NHS Trust for analyzing clinical samples. 


\section{REFERENCES}

1. Christian RC, Fitzpatrick LA. Vascular calcification. Current opinion in nephrology and hypertension 1999; 8: 443-448.

2. Blacher J, Safar ME, Guerin AP, Pannier B, et al. Aortic pulse wave velocity index and mortality in end-stage renal disease. Kidney international 2003; 63: 1852-1860.

3. London GM. Cardiovascular calcifications in uremic patients: clinical impact on cardiovascular function. J Am Soc Nephrol 2003; 14: S305-309.

4. Demer LL, Tintut Y. Mineral exploration: search for the mechanism of vascular calcification and beyond: the 2003 Jeffrey M. Hoeg Award lecture. Arterioscler Thromb Vasc Biol 2003; 23: 1739-1743.

5. Chen NX, O'Neill KD, Duan D, Moe SM. Phosphorus and uremic serum upregulate osteopontin expression in vascular smooth muscle cells. Kidney international 2002; 62: 1724-1731.

6. Wileman SM, Mann GE, Baydoun AR. Induction of L-arginine transport and nitric oxide synthase in vascular smooth muscle cells: synergistic actions of proinflammatory cytokines and bacterial lipopolysaccharide. British journal of pharmacology 1995; 116: 3243-3250.

7. Kanno Y, Into T, Lowenstein CJ, Matsushita K. Nitric oxide regulates vascular calcification by interfering with TGF-signalling. Cardiovascular research 2008; 77: 221-230.

8. Thakur S, Baydoun A. Post-transcriptional divergence in the regulation of CAT2A, CAT-2B and iNOS expression by dexamethasone in vascular smooth muscle cells. Amino Acids 2011: 1-10.

9. Du Y, Gao C, Liu Z, Wang L, et al. Upregulation of a Disintegrin and Metalloproteinase With Thrombospondin Motifs-7 by miR-29 Repression Mediates Vascular Smooth Muscle Calcification. Arterioscler Thromb Vasc Biol 2012; 32: 2580-2588.

10. Kircelli F, Peter ME, Sevinc Ok E, Celenk FG, et al. Magnesium reduces calcification in bovine vascular smooth muscle cells in a dose-dependent manner. Nephrol Dial Transplant 2011; 27: 514-521.

11. Jono S, Ikari $\mathrm{Y}$, Shioi $\mathrm{A}$, Mori $\mathrm{K}$, et al. Serum osteoprotegerin levels are associated with the presence and severity of coronary artery disease. Circulation 2002; 106: 1192-1194. 
12. Roos M, Lutz J, Salmhofer H, Luppa $P$, et al. Relation between plasma fibroblast growth factor-23, serum fetuin-A levels and coronary artery calcification evaluated by multislice computed tomography in patients with normal kidney function. Clinical endocrinology 2008; 68: 660-665.

13. Moe SM, Duan D, Doehle BP, O'Neill KD, et al. Uremia induces the osteoblast differentiation factor Cbfa1 in human blood vessels. Kidney international 2003; 63: 1003-1011.

14. Jono S, McKee MD, Murry CE, Shioi A, et al. Phosphate regulation of vascular smooth muscle cell calcification. Circ Res 2000; 87: E10-17.

15. Kestenbaum B. Phosphate metabolism in the setting of chronic kidney disease: significance and recommendations for treatment. Seminars in dialysis 2007; 20: 286-294.

16. El-Abbadi MM, Pai AS, Leaf EM, Yang HY, et al. Phosphate feeding induces arterial medial calcification in uremic mice: role of serum phosphorus, fibroblast growth factor-23, and osteopontin. Kidney international 2009; 75: 1297-1307.

17. Goldsmith DJA, Covic AC, Venning MC, Ackrill P. Ambulatory blood pressure monitoring in renal dialysis and transplant patients. American Journal of Kidney Diseases 1997; 29: 593-600.

18. London GM, Marty C, Marchais SJ, Guerin AP, et al. Arterial calcifications and bone histomorphometry in end-stage renal disease. J Am Soc Nephrol 2004; 15: 1943-1951.

19. Adragao $T$, Pires $A$, Lucas $C$, Birne $R$, et al. A simple vascular calcification score predicts cardiovascular risk in haemodialysis patients. Nephrol Dial Transplant 2004; 19: 1480-1488.

20. Palmer SC, Hayen A, Macaskill P, Pellegrini F, et al. Serum levels of phosphorus, parathyroid hormone, and calcium and risks of death and cardiovascular disease in individuals with chronic kidney disease: a systematic review and meta-analysis. JAMA 2011; 305: 1119-1127.

21. Bucay N, Sarosi I, Dunstan CR, Morony S, et al. osteoprotegerin-deficient mice develop early onset osteoporosis and arterial calcification. Genes \& development 1998; 12: 1260-1268.

22. Price PA, Buckley JR, Williamson MK. The amino bisphosphonate ibandronate prevents vitamin $\mathrm{D}$ toxicity and inhibits vitamin D-induced calcification of arteries, cartilage, lungs and kidneys in rats. J Nutr 2001; 131: 2910-2915. 
23. Nitta K, Akiba T, Suzuki K, Uchida K, et al. Effects of cyclic intermittent etidronate therapy on coronary artery calcification in patients receiving long-term hemodialysis. Am J Kidney Dis 2004; 44: 680-688.

24. Morena $\mathrm{M}$, Terrier $\mathrm{N}$, Jaussent $\mathrm{I}$, Leray-Moragues $\mathrm{H}$, et al. Plasma osteoprotegerin is associated with mortality in hemodialysis patients. J Am Soc Nephrol 2006; 17: 262-270.

25. Schoppet M, Preissner KT, Hofbauer LC. RANK ligand and osteoprotegerin: paracrine regulators of bone metabolism and vascular function. Arterioscler Thromb Vasc Biol 2002; 22: 549-553.

26. Combes C, Rey C, Freche M. In vitro crystallization of octacalcium phosphate on type I collagen: influence of serum albumin. Journal of materials science 1999; 10: 153-160.

27. Fakhrzadeh H, Ghaderpanahi M, Sharifi F, Badamchizade Z, et al. Increased risk of chronic kidney disease in elderly with metabolic syndrome and high levels of C-reactive protein: Kahrizak Elderly Study. Kidney \& blood pressure research 2009; 32: 457-463. 
Table 1: Biochemical parameters of serum from controls and CKD subjects

$\mathrm{NS}=$ non-significant, $\mathrm{SBP}=$ systolic blood pressure, $\mathrm{DBP}=$ diastolic blood pressure, eGFR $\left(\mathrm{ml} / \mathrm{min} / 1.73 \mathrm{~m}^{2}\right)=$ estimated glomerular filtration rate calculated using MDRD 4 formula, $\mathrm{CRP}=\mathrm{C}$-reactive protein, $\mathrm{BAP}=$ bone specific alkaline phosphatase, $\mathrm{PTH}=$ parathyroid hormone, OPG = osteoprotegerin, RANKL = receptor activator of nuclear factor kappa B ligand, MGP = matrix Gla protein. Normally distributed parameters represented as mean \pm standard deviation. Non-normally distributed parameters represented as median (minimum, maximum). ${ }^{*} p<0.05 ;{ }^{* *} p<0.01 ;{ }^{\dagger} p<0.001$ denote significant difference from controls by ANOVA.

\section{Table 2: Correlation coefficients of serum calcific potential with biomarkers}

Serum PTH = serum parathyroid hormone, serum OPG = serum osteoprotegerin and eGFR $\left(\mathrm{ml} / \mathrm{min} / 1.73 \mathrm{~m}^{2}\right)=$ estimated glomerular filtration rate calculated using MDRD 4 formula. Calcification potential values were correlated with particular biochemical variables using Pearson's or Spearman correlation as appropriate.

\section{Figure 1: Induction of calcification and assay for cytotoxicity in RASMCs.}

Cells cultured to $60 \%$ confluency were incubated for 5 days with either complete culture medium alone (Control; open bar), media containing $7 \mathrm{mM} \mathrm{CaCl}_{2}, 7 \mathrm{mM} \beta$-GP (solid bars) or a combination of both (Panel A). In parallel studies cells were incubated with $7 \mathrm{mM}$ $\mathrm{CaCl}_{2}$ plus $7 \mathrm{mM} \beta$-GP for different time points (Panel C). Calcification was quantified and normalised for total cell protein as described in the methods. The formation of calcific plaques was visualised under an inverted microscope at $\times 40$ magnification and the photograph (Panel B) is representative of at least 3 independent experiments. Changes in cell viability was determined as described in methods and represented in Panel $D$. The data is the mean \pm SEM from 3 experiments with 5 replicates in each. denotes $p<0.05, \cdots$ denotes $p<0.01, \cdots$ denotes $p<0.001$ when compared to controls $(C)$.

\section{Figure 2: Calcification of RASMC by serum from patients with CKD.}

Cells cultured to $60 \%$ confluency were incubated for 5 days with complete culture medium and $10 \%$ serum from controls (open bar) or from subjects with CKD3, CKD4/5 or on haemodialysis (solid bars). Calcification was quantified and normalised for total cell protein as described in the methods. The data represents the mean \pm SEM from 3 experiments with 5 replicates in each. $\cdot$ denotes $p<0.05, \bullet$ denotes $p<0.01, \cdots$ denotes $p<0.001$ statistical significance.

\section{Figure 3: Effects of $\mathrm{CaCl}_{2}$ and $\beta$-GP on serum-induced calcification.}

Cells cultured to $60 \%$ confluency were incubated for 5 days with complete culture medium containing $10 \%$ control (open bar) or CKD Sera in the absence (solid black bars) and presence of $\mathrm{CaCl}_{2}(7 \mathrm{mM})$ and $\beta$-GP $(7 \mathrm{mM})$ (hatched bars). Calcification was quantified and normalised for total cell protein as described in the methods. The data 
represents the mean \pm SEM from 3 experiments with 5 replicates in each. $\cdot$ denotes $p<0.01$ statistical significance.

Figure 4: Effects of $\mathrm{CaCl}_{2}$ and $\beta$-GP on serum-induced calcification in responders and non-responders.

Cells cultured to $60 \%$ confluency were incubated with (hatched bars) or without $\mathrm{CaCl}_{2}$ $(7 \mathrm{mM})$ and $\beta$-GP $(7 \mathrm{mM})$ (solid bars) for 5 days in complete culture medium containing $10 \%$ Serum from subjects on haemodialysis. Calcification was quantified and normalised for total cell protein as described in the methods. The data represents the mean \pm SEM from 3 experiments with 5 replicates in each. • denotes $p<0.05$ statistical significance. 
Table 1: Biochemical parameters of serum from controls and CKD subjects

\begin{tabular}{|c|c|c|c|c|c|c|c|}
\hline \multirow[t]{2}{*}{ Variables } & \multicolumn{7}{|c|}{ Groups } \\
\hline & $\begin{array}{l}\text { Control } \\
\text { (C) }\end{array}$ & $\begin{array}{l}\text { Moderate } \\
\text { CKD } \\
\text { (M) }\end{array}$ & $\begin{array}{l}\text { Advanced } \\
\text { CKD } \\
\text { (A) }\end{array}$ & $\begin{array}{c}\text { Haemodialysis } \\
\text { (HD) }\end{array}$ & $\begin{array}{c}\text { M v A } \\
\text { p-value }\end{array}$ & $\begin{array}{l}\text { M v HD } \\
\text { p-value }\end{array}$ & $\begin{array}{l}\text { A v HD } \\
\text { p-value }\end{array}$ \\
\hline Number & 20 & 21 & 18 & 30 & NS & NS & NS \\
\hline Age (yrs) & $63 \pm 6.2$ & $64 \pm 9.8$ & $66 \pm 17$ & $64 \pm 14$ & NS & NS & NS \\
\hline Gender (M:F) & $12 / 8$ & $15 / 6$ & $10 / 8$ & $22 / 10$ & NS & NS & NS \\
\hline SBP $(\mathrm{mmHg})$ & $150 \pm 24$ & $145 \pm 13$ & $152 \pm 27$ & $134 \pm 17$ & NS & NS & 0.026 \\
\hline $\mathrm{DBP}(\mathrm{mmHg})$ & $87 \pm 9$ & $85 \pm 12$ & $89 \pm 11$ & $73 \pm 11^{\dagger}$ & NS & 0.002 & $<0.001$ \\
\hline Creatinine (umol/l) & $72 \pm 17$ & $150 \pm 29$ & $291 \pm 80^{\dagger}$ & $751 \pm 235^{\dagger}$ & 0.017 & $<0.001$ & $<0.001$ \\
\hline eGFR (MDRD 4) & $94 \pm 24$ & $42 \pm 8^{\dagger}$ & $19 \pm 5^{\dagger}$ & NA & $<0.001$ & NA & NA \\
\hline Urea (mmol/l) & $5.2 \pm 1.2$ & $10.3 \pm 2.4^{\star *}$ & $20.3 \pm 6^{\dagger}$ & $20.7 \pm 6^{\dagger}$ & $<0.001$ & $<0.001$ & NS \\
\hline Haemoglobin (g/dl) & $14.0 \pm 1.0$ & $12.7 \pm 2.4$ & $11.2 \pm 2$ & $11.1 \pm 1.1^{* *}$ & NS & 0.010 & NS \\
\hline High CRP \% & 15 & 33 & 22 & $50^{*}$ & NS & NS & 0.016 \\
\hline Calcium(mmol/l) & $2.49 \pm 0.13$ & $2.41 \pm 0.12$ & $2.37 \pm 0.1$ & $2.37 \pm 0.2$ & NS & NS & NS \\
\hline Cholesterol (mmol/l) & $5.8 \pm 1.0$ & $4.8 \pm 1.1^{*}$ & $4.6 \pm 1.0^{\star *}$ & $4.1 \pm 1.2^{\dagger}$ & NS & NS & NS \\
\hline HDL Cholesterol (mmol/l) & $1.5 \pm 0.3$ & $1.2 \pm 0.3$ & $1.4 \pm 0.4$ & $1.3 \pm 0.6$ & NS & NS & NS \\
\hline Phosphate (mmol/l) & $1.02 \pm 0.15$ & $1.11 \pm 0.24$ & $1.34 \pm 0.26^{*}$ & $1.66 \pm 0.47^{\dagger}$ & NS & $<0.001$ & 0.010 \\
\hline Albumin (g/l) & $45.4 \pm 2.5$ & $41.1 \pm 4.7^{\star *}$ & $41.8 \pm 4.8^{*}$ & $37.4 \pm 2.9^{* *}$ & NS & 0.005 & 0.001 \\
\hline BAP (IU/I) & - & $26.2 \pm 6.4$ & $28.6 \pm 6.8$ & $24.1 \pm 6.7$ & NS & NS & NS \\
\hline PTH (pmol/l) & $4.0(2.3,6.1)$ & $3.0(1.2,22.9)$ & $5.6(1.9,25.6)$ & $17.8(1.0,43.7)^{\dagger}$ & NS & $<0.001$ & $<0.001$ \\
\hline OPG (pmol/l) & $4.0 \pm 1.5$ & $5.4 \pm 1.7$ & $5.8 \pm 2.2$ & $9.8 \pm 3.7^{\dagger}$ & NS & $<0.001$ & $<0.001$ \\
\hline RANKL (pmol/l) & $0.0(0,0.44)$ & $0.05(0,0.47)^{\dagger}$ & $0(0,0.42)^{\dagger}$ & $0.02(0,0.37)^{\dagger}$ & NS & NS & NS \\
\hline OPG RANKL Ratio & $75.7(7.4,291)$ & $12.7(5.3,41.2)^{\dagger}$ & $15.9(6.1,71.5)^{\dagger}$ & $16.3(7.3,35.4)^{\dagger}$ & NS & NS & NS \\
\hline MGP (ng/ml) & $15.4 \pm 1.4$ & - & - & $1.94 \pm 0.8$ & - & - & - \\
\hline
\end{tabular}


Table 2: Correlation coefficients of serum calcific potential with biomarkers

\begin{tabular}{|l|c|c|}
\hline \multicolumn{1}{|c|}{ Variables } & \multicolumn{2}{c|}{$\begin{array}{c}\text { Calcific potential of } \\
\text { serum }\end{array}$} \\
\cline { 2 - 3 } & Coefficient & p-value \\
\hline Serum Creatinine & 0.725 & $<0.001$ \\
\hline Blood urea & 0.600 & $<0.001$ \\
\hline Serum PTH & 0.455 & $<0.001$ \\
\hline Serum OPG & 0.419 & $<0.001$ \\
\hline Serum phosphate & 0.539 & $<0.001$ \\
\hline MDRD eGFR & -0.551 & $<0.001$ \\
\hline $\begin{array}{l}\text { Diastolic blood } \\
\text { pressure }\end{array}$ & -0.411 & $<0.001$ \\
\hline Haemoglobin & -0.382 & $<0.001$ \\
\hline Serum albumin & -0.451 & $<0.001$ \\
\hline
\end{tabular}


Figure 1

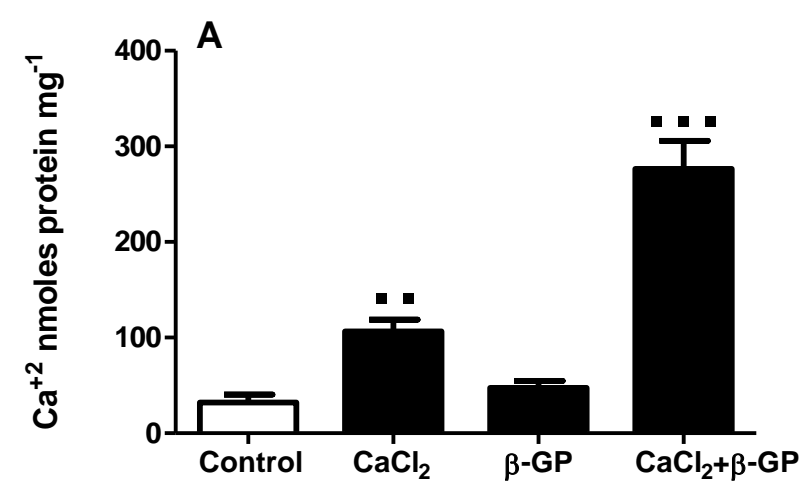

B
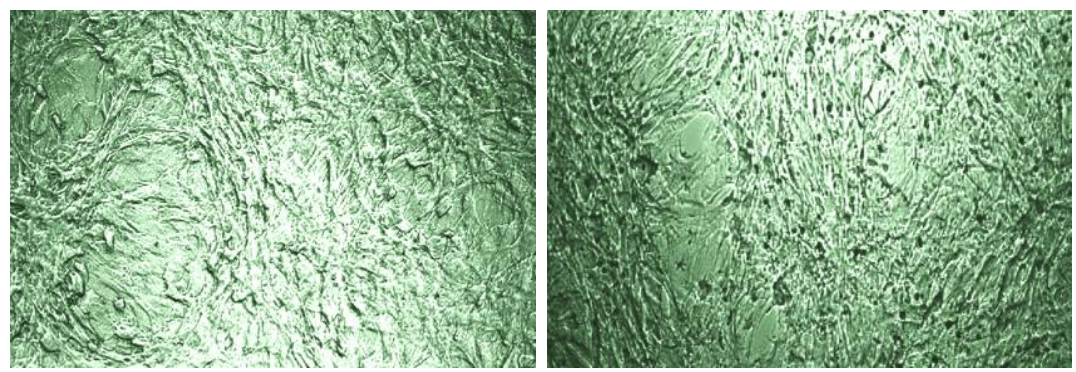

Control

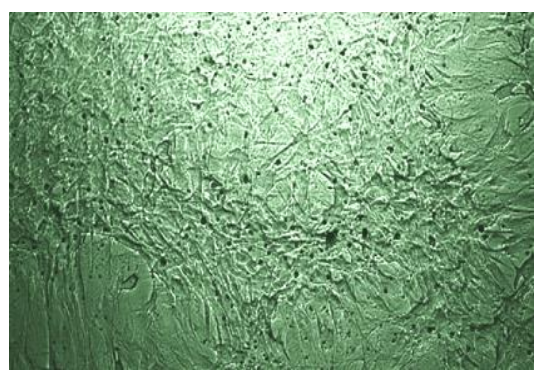

$\beta-G P$

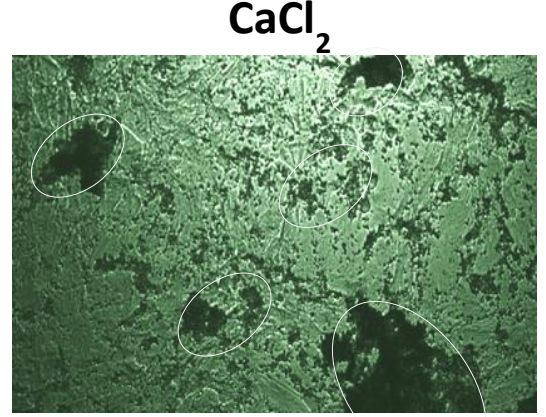

$\mathrm{CaCl}_{2}+\boldsymbol{\beta}-\mathrm{GP}$

D
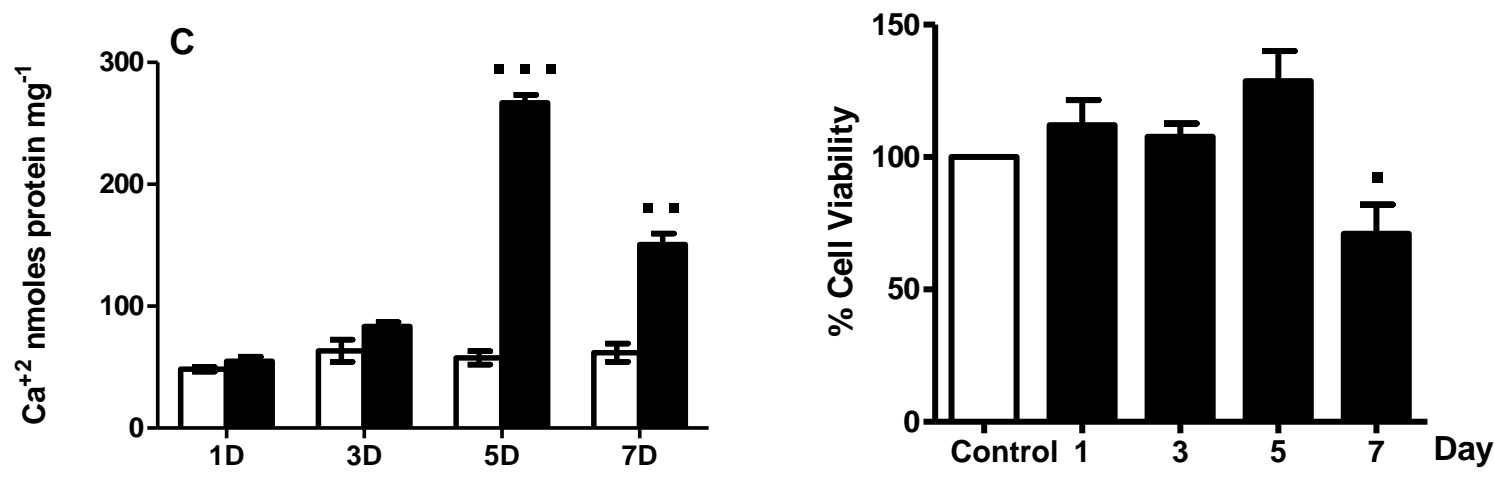
Figure 2

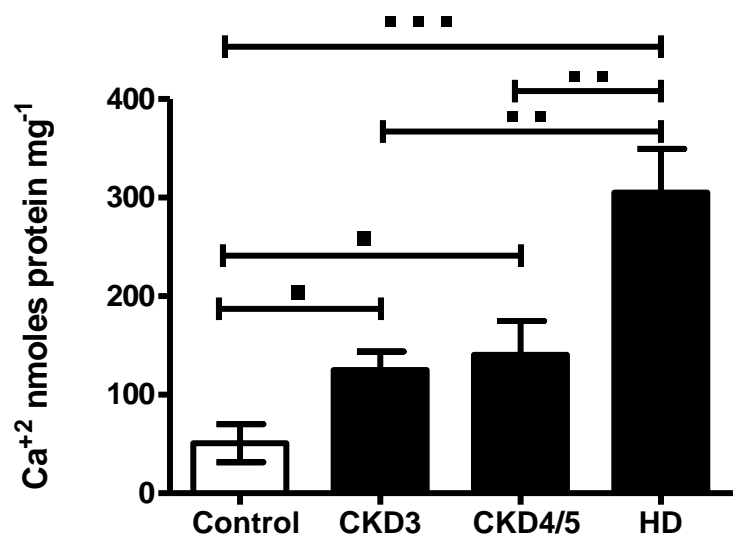

Figure 3

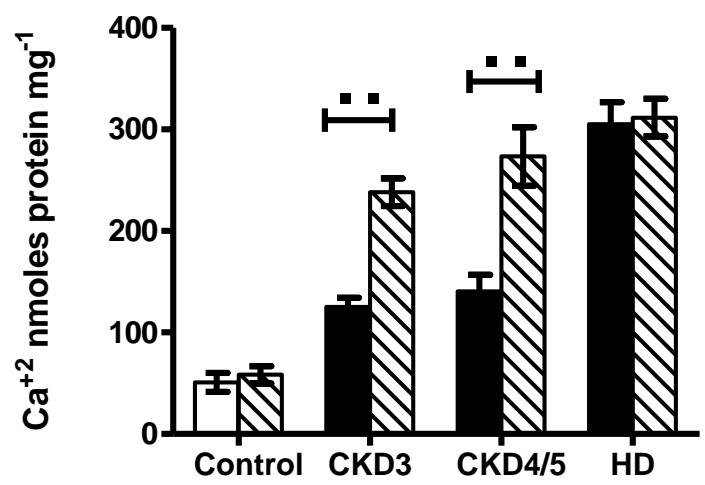

Figure 4

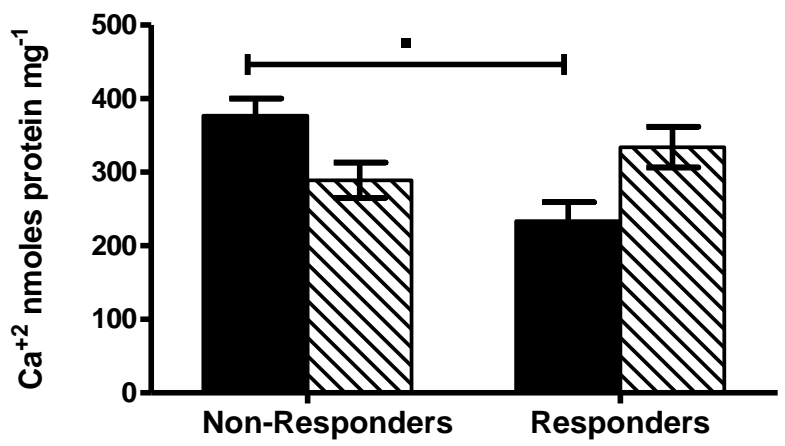

